\title{
Duodenal perforation by an inferior vena cava filter
}

\author{
Kunal Kishor Jha, ${ }^{1}$ Lokendra K Thakur, ${ }^{1}$ Sweta Jha ${ }^{2}$
}

${ }^{1}$ Department of Critical Care Medicine, Geisinger Medical Center, Danville, Pennsylvania, USA

${ }^{2}$ New York Medical College, Valhalla, New York, USA

\section{Correspondence to}

Dr Kunal Kishor Jha, kunaljhamd@gmail.com

Accepted 14 February 2017

\section{CrossMark}

To cite: Jha KK, Thakur LK,
Jha S. BMJ Case Rep
Published online: [please
include Day Month Year]
doi:10.1136/bcr-2017-
219299

\section{DESCRIPTION}

A woman aged 47 years presented to the emergency department with symptoms of fever, sudden-onset severe stabbing epigastric pain accompanied by nausea and non-bloody vomiting emesis. The patient had a medical history of recurrent abdominal pain and reflux which was treated with proton pump inhibitors. Owing to recurrent deep vein thrombosis and contraindications to anticoagulants, an inferior vena cava (IVC) filter was implanted 20 years prior. CT scan revealed IVC filter with prongs in the duodenum. Oesophagogastroduodenoscopy revealed a metallic foreign body projecting through the posterior wall of the duodenum, into the lumen, with surrounding erythema and oedema with minimal bleeding at the site of perforation (figure 1).

The patient underwent laparotomy and venotomy. The IVC filter was retrieved and subsequent ligation of IVC was performed. Intraoperative findings were suggestive of presence of a large infected phlegmon around the area of IVC. The procedure was complicated by MRSA bacteraemia and was treated with 6 weeks of daptomycin. She returned for follow-up and first postoperative visit on week 8 showed no symptoms of abdominal pain, nausea, vomiting or other symptoms of reflux.

IVC filters are mechanical adjuncts used to prevent pulmonary embolism. They are prescribed to patients with recurrent venous thromboembolism, despite adequate anticoagulation, complication of anticoagulation or inability to maintain/achieve adequate anticoagulation. ${ }^{1}$ The use of these filters has increased greatly over the past two decades. Potential complications of IVC filters include migration of the filter or its parts, arterial or venous perforation, fracture of the strut or protrusion into surrounding structures such as duodenum, large intestine, aorta, portal veins, diaphragm and the retroperitoneum. ${ }^{2}$ Although IVC perforation is common, duodenal perforation by an IVC filter is rare and it can present as sudden-onset severe epigastric pain, small bowel obstruction, gastro- intestinal haemorrhage or cavaduodenal fistula. ${ }^{1}$ Indications for open retrieval are bleeding, intestinal obstruction and sepsis. ${ }^{3}$

IVC filters are safe but can cause clinically significant complications, particularly during periods of extended implantation. Owing to low retrieval rates, there has been an increase in complications; therefore, filters should be removed as early as clinically feasible. Physicians should be aware that IVC filter migration may occur as a late complication, although based on the literature review, they may or may not cause symptoms. Decisions on removal should weigh the likelihood that it is causing symptoms against the risks of surgical removal.

\section{Learning points}

Physicians should have a high clinical suspicion for inferior vena cava (IVC) perforation through the duodenum if a patient with an IVC implant presents with atypical or sudden-onset severe epigastric pain, obstructed gastrointestinal symptoms or gastrointestinal bleed.

- Patients with delayed IVC penetration have non-specific clinical presentation; hence, detailed history and abdominal imaging can lead to a prompt diagnosis.

- Further studies should be performed to investigate the optimal timing of removal of IVC filters weighing the risks of long-term placement against the risks of potentially removing it too early.

Contributors LKT and KKJ assembled the case history and investigations from hospital records, analysed the data and wrote the paper. SJ selected the case and critically reviewed the paper.

Competing interests None declared.

Patient consent Obtained.
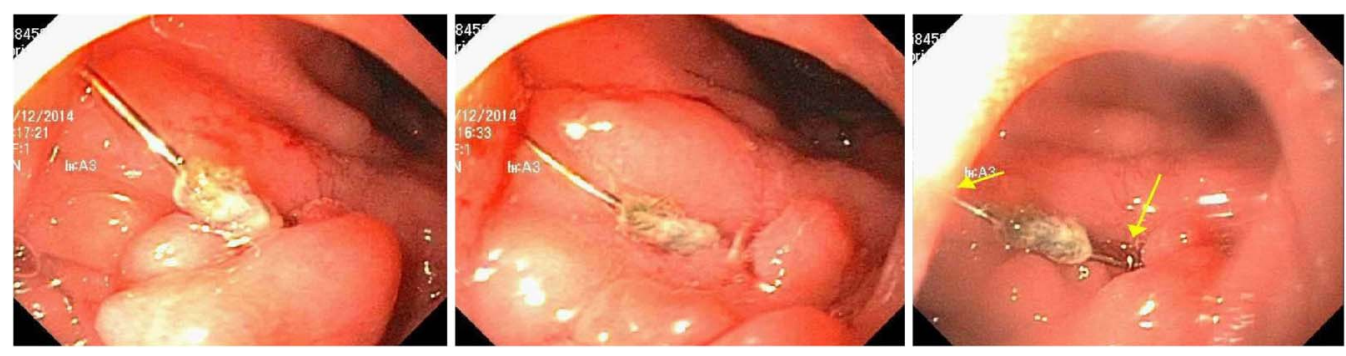

Figure 1 Upper gastrointestinal endoscopy revealing metallic struts projecting through the posterior wall of the duodenum, into the lumen, with surrounding erythema and oedema. 
Provenance and peer review Not commissioned; externally peer reviewed.

\section{REFERENCES}

1 Harvey JJ, Hopkins J, McCafferty IJ, et al. Inferior vena cava filters: what radiologists need to know. Clin Radiol 2013;68:721-32.
2 Dagenais F, Voisine P. Surgical removal of a 'nonretrievable' inferior vena cava filter: a unique case requiring a median sternotomy and cardiopulmonary bypass. Can J Cardiol 2009;25:e332-3.

3 Durack JC, Westphalen AC, Kekulawela S, et al. Perforation of the IVC: rule rather than exception after longer indwelling times for the Gunther Tulip and Celect retrievable filters. Cardiovasc Intervent Radiol 2012;35:299-308.

Copyright 2017 BMJ Publishing Group. All rights reserved. For permission to reuse any of this content visit http://group.bmj.com/group/rights-licensing/permissions.

BMJ Case Report Fellows may re-use this article for personal use and teaching without any further permission.

Become a Fellow of BMJ Case Reports today and you can:

- Submit as many cases as you like

- Enjoy fast sympathetic peer review and rapid publication of accepted articles

- Access all the published articles

- Re-use any of the published material for personal use and teaching without further permission

For information on Institutional Fellowships contact consortiasales@bmjgroup.com

Visit casereports.bmj.com for more articles like this and to become a Fellow 